\title{
Safety Profile and Patient Satisfaction in an Egyptian Cardiac Critical Care Unit
}

\author{
Dr.Noha Mohamed Rashed Dr.Zeinab Mohamed Aysha Dr. Mohamed Amin Fakher \\ 1.Collage of Applied Medical Science- Misr University for science and Technology \\ 2.Faculty of Nursing Tanta University \\ 3.Cairo University, critical care department
}

\begin{abstract} in improving the safety culture the following Tools

1. Safety Culture Survey Assessment tool

2. Designed safety checklist

3. Patient Satisfaction Questionnaire (PSQ)

It included the following phases

- Assessment of the safety culture

- Development of the checklist

- Evaluation of the checklist
\end{abstract}

Background: Patient safety was one of the most important issues that arisen in health care management many studies were done at different cities to evaluate healthcare safety goals, the development of a checklist might help

Purpose: Our work aimed to Measure the patient satisfaction at CCU, and assess the patient safety culture at CCU and finally develop Patient safety Checklist to improve performance

Method: Our study was carried out in an adult Cardiac Critical care unit (CCU) at Tanta University hospital using

Results

Study results claim that safety culture are poor in CCU especially for involvement of staff in decision making, and the absent of Safety rules and procedure which not supported from top management. But the new established safety checklist arise the safety awareness among the CCU staff. Most of patients complaining of waiting time, insurance coverage, care services, availability resources and perfection. Furthermore many physicians skills need more training to "be careful with patient's complain, Explaining the diagnosis and treatment strategies with patients, be good listener's, and Explain the medical terms". Finally, patients feel insecure for all medical problems.

Keywords: Safety goals- cardiac critical care- patient satisfaction-checklist

DOI: $10.7176 / \mathrm{JHMN} / 62-07$

Publication date:May $31^{\text {st }} 2019$

\section{I- Introduction}

Culture refers to shared values (what is important) and beliefs (what is held to be true) that interact with a system's structures and control mechanisms to produce behavioral norms. It influences patient safety directly by determining accepted practices and indirectly by acting as a barrier or enabler to the adoption of behaviors that promote patient safety. Understanding the components and influencers of culture and assessing the safety culture is essential to developing strategies that creates a culture committed to providing the safest possible care for patients. (Margret Hardet, 2015)

Patient safety was one of the most important issues that arisen in health care management in Egypt, many studies were done at different cities to evaluate healthcare safety goals. According to Medical Research Institute 2016 at Alexandria University, health governances unit, the surveyors represent results based on Egyptian health care accreditation program for hospital standard stated that general patient safety adherence was $50 \%$ and $44 \%$ for Egyptian patient safety standard. (Health governance 2016)

Cairo university and Ain Shams teaching hospital, reported that patient safety assessment among different health care providers based on 12 dimensions showed for example, learning improvement $78.2 \%$, teamwork $58.1 \%$, and non-punitive response 19.5\%.(Abou-Fotoh et al 2012)

On the other hand, Beni-Suef University hospital claim that overall average positive respond score of safety culture was $39.30 \%$. They contributed this results for different dimension, highest scores for team work 57.4\%, manger 53.5\% and others less than 50\% (Ekram M. 2017). Institute of Medicine (IOM) reported that medical errors kill between 44,000 and 98,000 patients in U.S. According to Martin Makary and Michael Danie, Medical Error is the third cause of death in US. (Duarte SCM, 2018).

New safety research stated that More people die from medical errors in a year than from highway accidents, breast cancer, or AIDS (Zaheer S, 2018). The IOM committee recommended that healthcare organizations create an environment in which culture of safety is an explicit organizational goal, becomes a top priority, and is driven by leadership. (Zaheer S, 2018) 
The Agency for Healthcare Research and Quality (AHRQ) has defined, the safety culture of an organization as the invention of individual and group values, attitudes, perceptions, competencies, and patterns of behavior that control the commitment to, and the style and proficiency of, an organization's health and safety management.(Reis GAX. et al,2019)

The nursing staff has an essential role in the reduction of medical errors, since they work successively in care and represents, in most cases, the highest percentage of workers in health services. Furthermore, the staff nurses has more manipulation in the management. (Batista J, 2019)

\section{II-Aim of the study}

Our work aimed to

1. Measure the patient satisfaction at CCU.

2. Assess the patient safety culture at CCU.

3. Develop Patient safety Checklist based on 2018 patient safety goals of Joint Commission.

4. Reduce Patient risks.

\section{III-Methodology}

\section{1-Research design:}

Two designs were used by the researchers A Quasi-Experimental and a descriptive study were carried out in an adult Cardiac Critical care unit (CCU) at Tanta University hospital.

\section{2-Settings:}

At the Cardiac Critical Care Unit (CCU); Tanta University Hospital, with a full capacity of 40 beds, it is well equipped by emergency medication, equipment and experienced staff. The staff nursing team includes 20 B.Sc. nurses and 7 nursing technicians and 27 diploma nurse. CCU layout is U shaped, prepared by ECG monitor and $\mathrm{O} 2$ source for each bed. Four resident physicians are available per shift.

\section{3-Sample:}

A convenience sample was selected from a population on the basis of the staff who attended the morning shift and Bachelor degree in addition to the same sample from patients who were admitted in same period of the study in morning shift and cooperative to fill the forms.

Selective sample was selected In order to calculate the sample size; a previous survey was carried out during six days of the same month to determine the patient safety climate in CCU. This study was carried out in three phases and by three measurement tools to conduct the safety checklist at CCU as the following consequences.

4-Tools:

\section{Safety Culture Survey Assessment tool:}

It was a standard tool established by joint industry/Health and Safety Executive (HSE) Project and available free on line. It is support users in their assessment of the health and safety culture within their organization and describe in the main technical report in order to gain a complete picture staffs from all levels and job/task areas in the organization. As well as providing a rounded picture of the current safety climate, this may also help to identify different problems in different areas. The results can be presented in different ways. The questionnaire content: In general terms: Organizational Context; Social Environment; Individual Appreciation; and Work Environment. The questioner has a five point, Likert-type scale (ranging from strongly agree to strongly disagree)

\section{Designed safety checklist:}

Based on the available literature and our own experience and observations at different institutions in the Egypt and Middle East, founded that the Patient Safety Checklist Comes one of the most important task in patient cares. Leader considers the safety first priority for all hospital managing. Workshop was hold to developed checklist for routine care at CCU. It was adopted from the National Patient Safety Goals 2018. Validity evidence and reliability was examined through staff nurses.

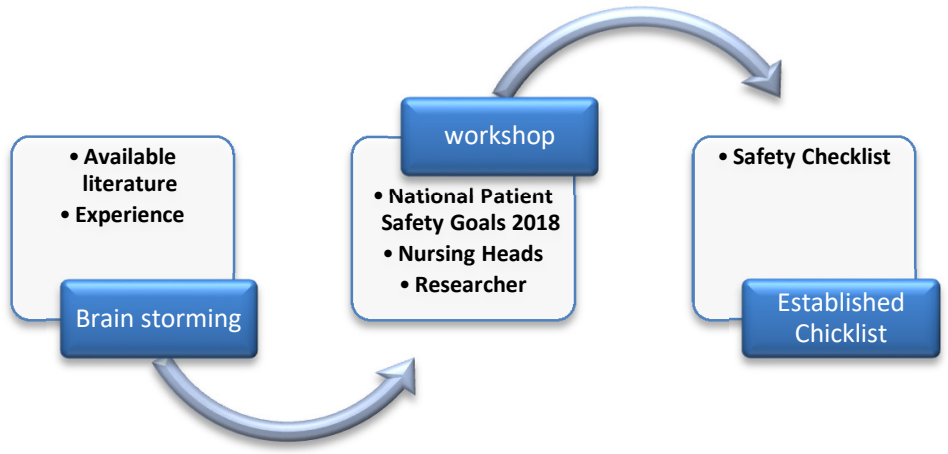

Figure 1 Established Safety Checklist 


\section{Patient Satisfaction Questionnaire (PSQ)}

It is standardized tool by Ware and his colleagues (Ware, Snyder, and Wright, 1976).It was modified by researcher as Egyptian culture, PSQ items that referred to all aspects of medical care in general were altered to refer the respondent's own medical care experiences. The criticism assess beliefs about medical care overall rather than satisfaction with one's own care. It is 50 items in the PSQ are used to score the PSQ subscales; each item appears in only one module. Item scoring rules depend on whether the item represents a favorable or unfavorable opinion about medical care. All subscales are scored, as the following high scores indicate greater satisfaction. Thus, given the preceding of item responses (where $1=$ strongly agree and $5=$ strongly disagree).

\section{5- Procedure and phases:}

\section{Phase 1(Assessment): Safety Culture Survey at Coronary care unit $\backslash$ Workplace assessment}

At this stage, the study was a descriptive study to assess baseline data of patient safety culture on workplace (CCU) used Safety Climate Measurement Tool. These measures issues have some indications of how staff nurses feels overall. Views and beliefs are shared among the staff. Additionally, Nurses attitudes is affecting, to some degree, how they behave at work; and evaluating attitudes to safety has driven an important indicator of an organization's safety climate.

Data were obtained from front-line nurses (Bachelor nurses) who worked in CCU at morning shift. Questionnaire was often distributed to staff by researcher. The objectives and nature of the study was introduced first, before staff are given time to complete the survey. After the initial safety climate assessment has been completed and interpreted, an action plan was developed, that linked to the organization's business plan, vision or mission. To show how was realistic of research goals.

Phase 2 (Implementation): Development and Implementation of Checklists at the Coronary Care Unit Workplace

Establishment of checklist included, CCU supervisor, quality nurse, infection control nurse, three head nurses, four staff nurses and one technician. The researcher and hospital supervisor was mediator. It started from $1^{\text {st }}$ of May to $15^{\text {th }}$ of the same month 2018. The discussion, was focused on identify patients correctly, improve staff communication, prevent infection, identify patient safety risks, and prevent mistakes in surgery. Finally conduct nine items for daily check by practical nurse to each patient. The sequence of checklists includes the following Major issues: Patient identification, Patient results, Medication, Use Patient alarms safely, Surgical safety, Site mark, ECG monitor, Patient connection, Patient allergy

It should be completed within a short period of time ( $<10$ minutes). For more than three months nurses got easily use every shift to remind them for important safety tasks and they verbally reported of many (near-miss) mistakes were prevented and became formally integrated into the normal workflow at CCU. This decision was supported by reports of events and Quality Office.

Phase 3(Evaluation): Provider Survey on Patient Satisfaction and their Perception after Using developed Patient Safety Checklists

Finally, to measure the adoption of the checklist, patient satisfaction survey was conducted as anonymous manual survey 6 months after implementation. The Patient Satisfaction (PSQ) is a 50-item survey that taps global satisfaction with medical care as well as satisfaction with six aspects of care: technical quality, interpersonal manner, communication, financial aspects of care, time spent with doctor, and accessibility of care. Some modification was done by researcher and translated into Arabic by Language college team of Misr University for Science and Technology. The survey was approved by CCU supervisor, and routine written informed consent was collected.

A total of 30 patients were randomly selected for the survey, to ensure the privacy of the respondents, the survey was strictly anonymous. After removing incomplete questionnaires, a total of respondents (30) from 37 admitted patients had successfully completed the questionnaire. Therefore, the final response rate for the survey was $81 \%$. Response options for each item ranged from 1 (disagree strongly) to 5 (agree strongly).

Transformed the five point response scale on the patient satisfaction survey to a 100 point scale and calculated means. The 100 point scale is better understood by hospital administrators and providers. Also calculated the percent positive patient satisfaction score: the percent of respondents in a clinical unit who responded 4 or 5 (agree or agree strongly) on the five point scale. 


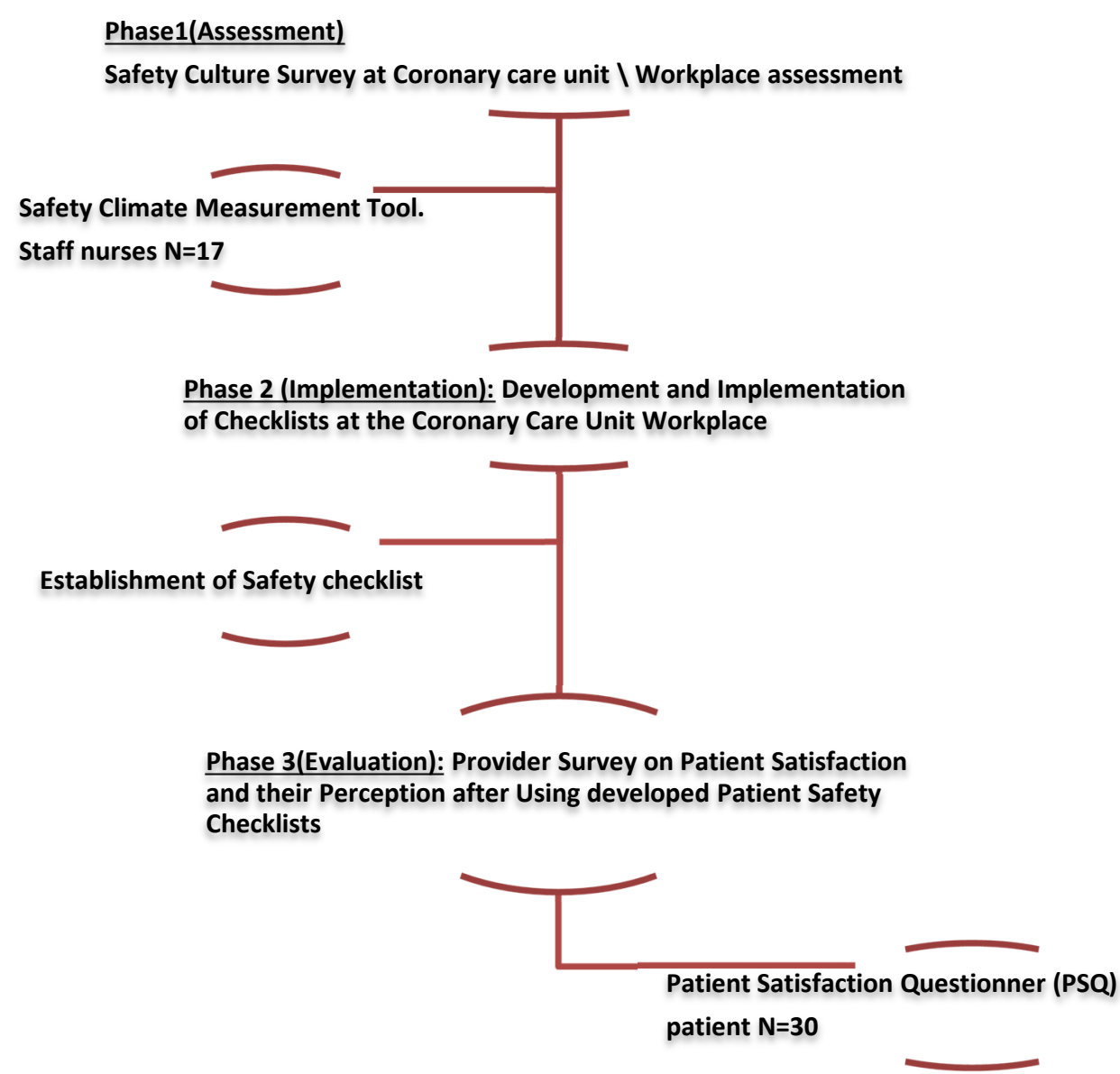

\section{Statistical analysis}

Figure 2 flow chart of phases and procedure of the safety profile study

The data collected were verified, coded and entered \& analysed using IBM Statistical Package for Social Science (SPSS) Statistics 22. For each indicator, frequencies or medians were calculated as appropriate. Continuous variables were presented as the median value of the indicator for all patients who were eligible for a given measure.

\section{IV-Results}

The attitude of health personnel towards patient safety was determined using the safety climate survey scoring system developed by the Institute for Health Improvement. A total of respondents (17) from 20 staff nurses had successfully completed the questionnaire. Therefore, the final response rate for the survey was $85 \%$. Response options for each item ranged from 1 (disagree strongly) to 5 (agree strongly). Transformed the five point response scale on the safety climate survey to a 100 point scale and calculated means. The 100 point scale is better understood by hospital administrators and providers. Also calculated the percent positive safety climate score: the percent of respondents in a clinical unit who responded 4 or 5 (agree or agree strongly) on the five point scale.

Table 1:

Personnel characteristics for CCU nurses involved in our study N (17)

\section{Personnel characteristics}

\section{Gender}

Male

Female

Age:

$25 \leq 35$

$36 \leq 45$

Degree

BS.C

Diploma
Numbers/percent

$\begin{array}{ll}7 & / 41.1 \% \\ 10 & / 50.9 \% \\ & \\ 11 & / 64.7 \% \\ 6 & / 35.3 \% \\ & \\ \mid 17 & / 100 \% \\ 0 & / 0 \%\end{array}$


Table 2: Descriptive statistics for each item scale of the Safety Climate assessment:

\begin{tabular}{|l|l|l|l|l|l|}
\hline Safety Climate items & Mean & Mean\% & Std. Deviation & P & Rank \\
\hline Management Commitment & 3.26 & $65 \%$ & 1.11 & $0.000^{*}$ & 2 \\
\hline Communication & 2.93 & $59 \%$ & 0.973 & $0.000^{*}$ & 4 \\
\hline Priority of Safety & 2.49 & $50 \%$ & 0.798 & 0.456 & 5 \\
\hline Safety Rules and Procedures & 2.33 & $70 \%$ & 0.79 & $0.000^{*}$ & 7 \\
\hline Supportive Environment & 3.96 & $79 \%$ & 0.97 & 0.001 & 1 \\
\hline Involvement in decision making & 1.89 & $38 \%$ & 0.86 & $0.001^{*}$ & 8 \\
\hline Personal Priorities and Need for Safety & 2.35 & $47 \%$ & 0.86 & $0.000^{*}$ & 6 \\
\hline Personal Appreciation of Risk & 2.99 & $60 \%$ & 1.31 & $0.000^{*}$ & 3 \\
\hline Work Environment & 2.93 & $0.59 \%$ & 2.93 & $0.000^{*}$ & 4 \\
\hline
\end{tabular}

Based on safety climate assessment (Table2) our results showed that nursing staff involvement in decision making has the lowest score of ranking among the others safety factors (1.89), then the absent of Safety rules and procedure (2.33) and Personal Priorities and Need for Safety (2.35).

Table 3:

Correlation among Safety Climates Items N= 17(we don't need this table only important results)???

\begin{tabular}{|c|c|c|c|c|c|c|c|c|c|c|}
\hline Correlations & $\begin{array}{l}\text { Management } \\
\text { Commitment }\end{array}$ & $\begin{array}{l}\text { Communic } \\
\text { ation }\end{array}$ & $\begin{array}{l}\text { Priority of } \\
\text { Safety }\end{array}$ & $\begin{array}{l}\text { Safety Rules } \\
\text { and Procedures }\end{array}$ & $\begin{array}{l}\text { Supportive } \\
\text { Environment }\end{array}$ & Involvement & $\begin{array}{l}\text { Personal Priorities and } \\
\text { Need for Safety }\end{array}$ & \begin{tabular}{|l|} 
Personal \\
Appreciation of \\
Risk
\end{tabular} & $\begin{array}{l}\text { Work } \\
\text { Environment }\end{array}$ & all \\
\hline Management Commitment & 1 & & & & & & & & & \\
\hline Communication & -.235 & 1 & & & & & & & & \\
\hline Priority of Safety & -318 & .232 & 1 & & & & & & & \\
\hline Safety Rules and Procedures & $.877^{* *}$ & -.289 & -360 & 1 & & & & & & \\
\hline Supportive Environment & $-.532^{*}$ & .213 & .349 & $-.661^{* *}$ & 1 & & & & & \\
\hline Involvement decision making & $-670^{*+}$ & -.190 & .388 & $-.743^{* *}$ & $.654^{* *}$ & 1 & & & & \\
\hline Personal Priorities and Need for Safety & $-.485^{*}$ & $.488^{*}$ & $.559^{*}$ & $-.668^{*}$ & $.689^{* *}$ & $.559^{*}$ & 1 & & & \\
\hline Personal Appreciation of Risk & $.779^{* *}$ & -.239 & -.225 & $.937^{* *}$ & $-.687^{* *}$ & $-.777^{+*}$ & $-.659^{* *}$ & 1 & & \\
\hline Work Environment & $.872^{* *}$ & -.176 & -178 & $.954^{*}$ & $-.598^{*}$ & $-.741^{* *}$ & $-.562^{*}$ & $.953^{* *}$ & 1 & \\
\hline all & $-.586^{\star}$ & $.523^{*}$ & $.672^{*+}$ & $-.769^{* *}$ & $.739^{* *}$ & $.637^{*+}$ & $.923^{* *}$ & $-.746^{*+}$ & $-.649^{* *}$ & 1 \\
\hline
\end{tabular}

**. Correlation is significant at the 0.01 level (2-tailed).

*. Correlation is significant at the 0.05 level (2-tailed).

Table (3) shows the relation among safety items as the following that there were strong relationship between safety rules and procedure, and personal appreciation at risk (.937). Additionally it determine that Work environment has a great effect for three main issues safety rules and procedures (.954), personnel appreciation at risk (.953), and management commitment (.872). Furthermore there was a big relation between personnel appreciation at risk and safety rules and procedure (.937)

\section{Second patient satisfaction survey}

To explore patient satisfaction towards healthcare service, we used the Short-Form Patient Satisfaction Questionnaire (PSQ-18), originally developed by Marshall and Hays and validated among Egypt population. This widely used self-reported tool assessed health service satisfaction at CCU. 
Table 4:

Descriptive statistics for patient satisfaction scale about CCU medical care system that including "Staff Nurse". N=30

\begin{tabular}{|c|c|c|c|c|c|c|c|c|c|}
\hline $\mathrm{NO}$ & ITEM & $\begin{array}{l}\text { Strongly } \\
\text { disagree }\end{array}$ & Disagree & $\begin{array}{l}\text { Neither } \\
\text { agree nor } \\
\text { disagre }\end{array}$ & Agree & $\begin{array}{l}\text { Strongly } \\
\text { agree }\end{array}$ & Mean & $\begin{array}{l}\text { Std. } \\
\text { D. }\end{array}$ & $\mathrm{p}$ \\
\hline & $\begin{array}{l}\text { I am very satisfied with the } \\
\text { medical care I receive here }\end{array}$ & $20.0 \%$ & $46.7 \%$ & $10.0 \%$ & $13.3 \%$ & $10.0 \%$ & 2.47 & 1.252 & 0.027 \\
\hline & $\begin{array}{l}\text { Medical care I receive here is } \\
\text { just about perfect }\end{array}$ & $46.7 \%$ & $33.3 \%$ & $20.0 \%$ & $0.0 \%$ & $0.0 \%$ & 1.73 & 0.785 & 0.000 \\
\hline & $\begin{array}{l}\text { During my medical visit I am } \\
\text { always allowed to say } \\
\text { everything I think is } \\
\text { important }\end{array}$ & $26.7 \%$ & $20.0 \%$ & $40.0 \%$ & $6.7 \%$ & $6.7 \%$ & 2.53 & 1.279 & 0.055 \\
\hline & $\begin{array}{l}\text { when I go for medical care } \\
\text { they are careful to check } \\
\text { everything when treating and } \\
\text { examining me }\end{array}$ & $40.0 \%$ & $20.0 \%$ & $26.7 \%$ & $10.0 \%$ & $3.3 \%$ & 2.17 & 1.177 & 0.001 \\
\hline & $\begin{array}{l}\text { The office hours are } \\
\text { convenient for me... }\end{array}$ & $40.0 \%$ & $23.3 \%$ & $23.3 \%$ & $13.3 \%$ & $0.0 \%$ & 2.10 & 1.094 & 0.000 \\
\hline & $\begin{array}{l}\text { there are things about the } \\
\text { medical system I receive my } \\
\text { care from that need to be } \\
\text { improved }\end{array}$ & $60.0 \%$ & $30.0 \%$ & $10.0 \%$ & $0.0 \%$ & $0.0 \%$ & 1.50 & 0.682 & 0.000 \\
\hline & $\begin{array}{l}\text { the medical staff that treats } \\
\text { me knows about the latest } \\
\text { medical developments }\end{array}$ & $20.0 \%$ & $30.0 \%$ & $26.7 \%$ & $16.7 \%$ & $6.7 \%$ & 2.60 & 1.192 & 0.076 \\
\hline & $\begin{array}{l}\text { I have easy access to the } \\
\text { medical specialist I need... }\end{array}$ & $36.7 \%$ & $10.0 \%$ & $26.7 \%$ & $13.3 \%$ & $13.3 \%$ & 2.57 & 1.455 & 0.114 \\
\hline & $\begin{array}{l}\text { Where I get medical care, } \\
\text { people have to wait too long } \\
\text { for emergency treatment. }\end{array}$ & $70.0 \%$ & $13.3 \%$ & $16.7 \%$ & $0.0 \%$ & $0.0 \%$ & 1.47 & 0.776 & 0.000 \\
\hline & $\begin{array}{l}\text { the amount I have to pay to } \\
\text { cover or insure my medical } \\
\text { care needs is reasonable }\end{array}$ & $53.3 \%$ & $26.7 \%$ & $20.0 \%$ & $0.0 \%$ & $0.0 \%$ & 1.67 & 0.802 & 0.000 \\
\hline & $\begin{array}{l}\text { There are some things about } \\
\text { the medical care I receive } \\
\text { that could be better }\end{array}$ & $53.3 \%$ & $36.7 \%$ & $10.0 \%$ & $0.0 \%$ & $0.0 \%$ & 1.57 & 0.679 & 0.000 \\
\hline & $\begin{array}{l}\text { Those who provide my } \\
\text { medical care sometimes } \\
\text { hurry too much when they } \\
\text { treat me }\end{array}$ & $53.3 \%$ & $26.7 \%$ & $13.3 \%$ & $6.7 \%$ & $0.0 \%$ & 1.73 & 0.944 & 0.000 \\
\hline & $\begin{array}{l}\text { When I am receiving medical } \\
\text { care, they should pay more } \\
\text { attention to my privacy }\end{array}$ & $63.3 \%$ & $23.3 \%$ & $10.0 \%$ & $3.3 \%$ & $0.0 \%$ & 1.53 & 0.819 & 0.000 \\
\hline & $\begin{array}{l}\text { I am able to get medical are } \\
\text { whenever I need it }\end{array}$ & $53.3 \%$ & $33.3 \%$ & $13.3 \%$ & $0.0 \%$ & $0.0 \%$ & 1.60 & 0.724 & 0.000 \\
\hline
\end{tabular}

Table 4 represents that most of the admitted patient at CCU disagree for medical care system by more than $60 \%$ indicated at many items as following 1,2 , and 10 . In addition items $6,9,11,12,13,14$, items of medical care system, also patients got disagree by more than $70 \%$. 
Table 5: Descriptive statistics for patient satisfaction scale about $\mathrm{CCU}$ Medical care giver, $\mathbf{N}=\mathbf{3 0}$

\begin{tabular}{|c|c|c|c|c|c|c|c|c|c|}
\hline $\mathrm{NO}$ & ITEM & $\begin{array}{l}\text { Disagree } \\
\text { Strongly } \\
\text { disagree }\end{array}$ & Disagree & $\begin{array}{l}\text { Neither } \\
\text { agree nor } \\
\text { disagree }\end{array}$ & Agree & $\begin{array}{l}\text { Strongly } \\
\text { agree }\end{array}$ & Mean & $\begin{array}{l}\text { Std. } \\
\text { Deviation }\end{array}$ & $\mathrm{p}$ \\
\hline & $\begin{array}{l}\text { Doctors need to be } \\
\text { more thorough in } \\
\text { treating and examining } \\
\text { me... }\end{array}$ & $46.7 \%$ & $36.7 \%$ & $10.0 \%$ & $3.3 \%$ & $3.3 \%$ & 1.80 & 0.997 & 0.000 \\
\hline & $\begin{array}{l}\text { Doctors are good } \\
\text { about explaining the } \\
\text { reason for medical } \\
\text { tests }\end{array}$ & $30.0 \%$ & $43.3 \%$ & $6.7 \%$ & $20.0 \%$ & $0.0 \%$ & 2.17 & 1.085 & 0.000 \\
\hline & $\begin{array}{l}\text { I think my doctor's } \\
\text { office has everything } \\
\text { need to provide } \\
\text { complete medical care }\end{array}$ & $23.3 \%$ & $36.7 \%$ & $23.3 \%$ & $10.0 \%$ & $6.7 \%$ & 2.40 & 1.163 & 0.008 \\
\hline & $\begin{array}{l}\text { Sometimes, doctors } \\
\text { make me wonder if } \\
\text { their diagnosis is } \\
\text { correct... }\end{array}$ & $26.7 \%$ & $20.0 \%$ & $40.0 \%$ & $6.7 \%$ & $6.7 \%$ & 2.47 & 1.167 & 0.018 \\
\hline & $\begin{array}{l}\text { Sometimes, doctors } \\
\text { use medical terms } \\
\text { without explaining } \\
\text { what they mean... }\end{array}$ & $63.3 \%$ & $16.7 \%$ & $20.0 \%$ & $0.0 \%$ & $0.0 \%$ & 1.57 & 0.817 & 0.000 \\
\hline & $\begin{array}{l}\text { Sometimes doctors } \\
\text { make me feel foolish }\end{array}$ & $66.7 \%$ & $16.7 \%$ & $16.7 \%$ & $0.0 \%$ & $0.0 \%$ & 1.50 & 0.777 & 0.000 \\
\hline & $\begin{array}{l}\text { Doctors never expose } \\
\text { me to unnecessary }\end{array}$ & $63.3 \%$ & $26.7 \%$ & $3.3 \%$ & $6.7 \%$ & $0.0 \%$ & 1.53 & 0.860 & 0.000 \\
\hline & $\begin{array}{l}\text { Some of the doctors I } \\
\text { have seen lack } \\
\text { experience with my } \\
\text { medical problems }\end{array}$ & $26.7 \%$ & $40.0 \%$ & $33.3 \%$ & $0.0 \%$ & $0.0 \%$ & 2.07 & 0.785 & 0.000 \\
\hline & $\begin{array}{l}\text { Doctors sometimes } \\
\text { ignore what I tell them }\end{array}$ & $30.0 \%$ & $26.7 \%$ & $43.3 \%$ & $0.0 \%$ & $0.0 \%$ & 2.13 & 0.860 & 0.000 \\
\hline & $\begin{array}{l}\text { Doctors rarely dive e } \\
\text { advice about ways lo } \\
\text { avoid illness and stay } \\
\text { health }\end{array}$ & $43.3 \%$ & $26.7 \%$ & $10.0 \%$ & $20.0 \%$ & $0.0 \%$ & 2.07 & 1.172 & 0.000 \\
\hline & $\begin{array}{l}\text { Doctors always do } \\
\text { their best to keep me } \\
\text { from worrying }\end{array}$ & $60.0 \%$ & $23.3 \%$ & $16.7 \%$ & $0.0 \%$ & $0.0 \%$ & 1.57 & 0.774 & 0.000 \\
\hline & $\begin{array}{l}\text { I have some doubts } \\
\text { about the ability of the } \\
\text { doctors who treat me }\end{array}$ & $60.0 \%$ & $33.3 \%$ & $6.7 \%$ & $0.0 \%$ & $0.0 \%$ & 1.47 & 0.629 & 0.000 \\
\hline & $\begin{array}{l}\text { Doctors listen } \\
\text { carefully to what I } \\
\text { have to say }\end{array}$ & $56.7 \%$ & $43.3 \%$ & $0.0 \%$ & $0.0 \%$ & $0.0 \%$ & 1.43 & 0.504 & 0.000 \\
\hline & $\begin{array}{l}\text { All things considered, } \\
\text { medical care I receive } \\
\text { from doctors is } \\
\text { excellent... }\end{array}$ & $70.0 \%$ & $20.0 \%$ & $10.0 \%$ & $0.0 \%$ & $0.0 \%$ & 1.40 & 0.675 & 0.000 \\
\hline & $\begin{array}{l}\text { My doctors are very } \\
\text { competent and well } \\
\text { trained }\end{array}$ & $46.7 \%$ & $30.0 \%$ & $23.3 \%$ & $0.0 \%$ & $0.0 \%$ & 1.77 & 0.817 & 0.000 \\
\hline
\end{tabular}

Table 5 shows the curve of patient satisfaction from doctor's skills, abilities, and care. Some patient trusted doctor's skills totally as represented at $15,19,20,22,23,26,29$, on another hand others patient have seen that doctors didn't competent enough at rest items. 
Table 6: Descriptive statistics for patient satisfaction scale about health care in Egypt, $\mathbf{N}=\mathbf{3 0}$

\begin{tabular}{|l|l|l|l|l|l|l|l|l|}
\hline ITEM & $\begin{array}{l}\text { Disagree } \\
\text { Strongly } \\
\text { disagree }\end{array}$ & Disagree & $\begin{array}{l}\text { Neither } \\
\text { agree nor } \\
\text { disagree }\end{array}$ & Agree & $\begin{array}{l}\text { Strongly } \\
\text { agree }\end{array}$ & Mean & $\begin{array}{l}\text { Std. } \\
\text { D }\end{array}$ & $\mathrm{p}$ \\
\hline $\begin{array}{l}\text { there is a crisis in health care } \\
\text { in Egypt today }\end{array}$ & $60.0 \%$ & $20.0 \%$ & $20.0 \%$ & $0.0 \%$ & $0.0 \%$ & 1.60 & 0.814 & 0.000 \\
\hline $\begin{array}{l}\text { I feel insure and protected } \\
\text { financially against all } \\
\text { possible medical problems }\end{array}$ & $43.3 \%$ & $43.3 \%$ & $6.7 \%$ & $6.7 \%$ & $0.0 \%$ & 1.77 & 0.858 & 0.000 \\
\hline $\begin{array}{l}\text { I find it hard to get an } \\
\text { appointment right away... }\end{array}$ & $46.7 \%$ & $40.0 \%$ & $13.3 \%$ & $0.0 \%$ & $0.0 \%$ & 1.67 & 0.711 & 0.000 \\
\hline
\end{tabular}

Table 6 represents that the health care system in Egypt need hard work for improvement and development as $80 \%$ of patient disagree for the health care system generally in Egypt.

\section{V-Discussion}

According to The World Health Organization (WHO), patient safety is defined as "the prevention of errors and adverse effects to patients associated with health care" and "to do no harm to patients. Millions of population globally who suffer disabilities, injuries or death each year due to dangerous medical practices (Lawati et al 2018)

The survey results, Based on safety climate assessment, stated that nursing staff of the CCU reported that the safety management variables ranking from lowest to highest as involvement in decision making was, the absent of Safety rules and procedure, Personal Priorities and Need for Safety. Those results showed the deficit on Top management for established strategies of patient safety. It is known that the organizations where the values are not stuck in the culture of safety, let's her patient tends to be high risks. Additionally the lack of awareness and the resistance to changes affect also the safety of workplace. (Kang J, Yun S., 2016)

A Kuwaitian study (2018) which covered 16 public hospital had little bite different results, it showed that, lowest ranking and requiring improvement as, teamwork across units, handoffs and transitions , overall perception of patient safety, frequency of events reported, communication openness, staffing and non-punitive response to error. And The dimensions with the highest positive score, Teamwork within Units, Organizational LearningContinuous Improvement, Management Support for Patient Safety, Supervisor/Manager Expectations \& Actions Promoting Patient Safety, and Feedback and Communication about Error (Ali et. al 2018)

Actually the survey grasped the attention of CCU staff to discuss different solution for solving the problem and promote a quality of care of patients.

The results had raised the relation between variables Safety rules and procedure and personnel appreciation at risk was evidence. Over all the nurse's participant expressed that the work environment plays the main effect for others variables safety rules and procedure, personnel appreciation at risk and management commitment. It was homogenous group for development of patient safety at any organization. This was encourage the management team to be motivated for designing a tool to promote the patient safety at CCU and to reduce the patient risk as well. This similar to protocol was done at two clinics of a dental teaching college in Riyadh. (Ahsan SH, 2019)

Intensive care unit is a risk area for medical errors. It was observed that medical teams were usually blamed. In the Human Error Theory, error is associated with two approaches: the person and the system approach, related to different philosophies of error management. The errors identified were related to the system approach, which considers that humans are fallible and errors are to be expected in all organizations and are associated with systemic factors (Duarte et al 2015).

Errors are classified according to the cognitive stage of occurrence and the action involved. They may be related to planning (mistakes), storage (lapses) and execution (slips) (Duarte et al 2015). Planning errors were related to the decision-making process or planning of the action, such as errors in the preparation of medications. Storage and execution errors were exemplified by not raising bed rails and improper handling of equipment. (Duarte, et al 2015)

Cognitive stages interrelate, and depending on the situation, errors can be associated with more than one stage. For example, a medication error can occur because it was prepared in the wrong way due to incorrect planning of the action (mistake), improperly stored in the sector (lapse) and administered outside of the prescribed time, in the wrong patient, wrong route or wrong technique (slip) (Lee, Y., Yang, C., \& Chen, T. 2016)

Discussion arises, however, whether and how patients should be involved in the audit process (Lee, Y., Yang, C., \& Chen, T. 2016). Our findings show that patient participation in an audit team is not as easy as it seems. Especially medical department heads and directors of quality departments seem to lean towards the fact that bias, lack of knowledge and the risk of not securing confidentiality are barriers for involving patient in the audit team. It is curious that the different, more subjective patient experiences are valued less, while confidentiality is not an exclusive characteristic of healthcare professionals. 
Our study divided the results of patient satisfaction to three parts. Part 1 measuring the satisfaction of medical care system including the quality of nursing care. More than $60 \%$ of patients reported that medical system need to improve in many issues e.g. (waiting time, insurance coverage, care services, availability resources and perfection). These results were concordant to a study conducted in China 2019. Where, Patients safety culture was shaped by organizational and individual characteristics. (Wang Y, etl. 2019). Another study reported in state that $46 \%$ of nurses complained that mistakes are held against them and $28 \%$ do not feel safe questioning authority regarding unsafe practices. (Agosto PD. 2018)

In part II, our results showed that patients prescribed doctors skills in CCU that they lack experience and need more training to "be careful with patient's complain, Explaining the diagnosis and treatment strategies with patients, be good listener's, Explain the medical terms". This was discordant to a study conducted in Cairo University where the majority of participants were physicians which were working staff composition in any governmental Egyptian health care organization where physicians and nurses' ratio almost represents 2:1 of the working force (El shafei, 2019). Also in the Brazilian study which refers to that Physician was having the best predictors of perceptions of safety in the general. (Magalhães, 2019)

On another hand Part III, determined the patients perception overall medical care at Egypt. About $80 \%$ stated that the medical care is in a Crisis. They feel insecure for all medical problems, especially that medical insurance and medical care services weren't available for all patient categories. The medical insurance low still not approved from Board of Government.

\section{Study limitation}

1-Being single center study limit the benchmarking with other centers.

2- Evaluation of patient's satisfaction should have been reevaluated six months later to measure the long term impact of improvement

\section{VI-Conclusion}

Study results claim that safety culture are poor in CCU especially for involvement of staff in decision making, and the absent of Safety rules and procedure which not supported from top management. But the new established safety checklist arise the safety awareness among the CCU staff. Most of patients complaining of waiting time, insurance coverage, care services, availability resources and perfection. Furthermore many physicians skills need more training to "be careful with patient's complain, Explaining the diagnosis and treatment strategies with patients, be good listener's, and Explain the medical terms”. Finally, patients feel insecure for all medical problems.

\section{VII-References:}

1. Abou-foutouh, Ismail et al (2012): Assessment of patient safety culture among health care providers at teaching hospital in Cairo- Egypt

2. Agosto PD, Ely E, Bettencourt AP, Schierholz ES, Frankenberger WD, Catania G, Aiken LH ( 2018) : The Association of the Nurse Work Environment and Patient Safety in Pediatric Acute Care. Lake ET, Roberts KE1, . J Patient Saf. 2018 Dec 28. doi: 10.1097/PTS.0000000000000559

3. Ahsan SH, Abdul Wahid AQ, Alali S, ALlqadhi A, Alnakly Z, Al-Turki M, Hassan MA, Almarshd A., (2019): A comparison of patient safety culture at two campuses of Riyadh based dental College. J Pak Med Assoc.;69 (1):72-76.

4. Ali, H., Ibrahem, S. Z., Al Mudaf, B., Al Fadalah, T., Jamal, D., \& El-Jardali, F. (2018). Baseline assessment of patient safety culture in public hospitals in Kuwait. BMC Health Services Research, 18(1), 158. doi:10.1186/s12913-018-2960-x

5. Batista J, Cruz EDA, Alpendre FT, Paixao DPSS, Gaspari AP, Mauricio AB. (2019) :Safety culture and communication about surgical errors from the perspective of the health team. Rev Gaucha .Enferm.;40 (esp):e20180192.doi: https://doi.org/10.1590/1983-1447.2019.20180192.

6. Duarte SCM, Stipp MAC, Cardoso MMVN, Büscher A.(2018): Patient safety: understanding human error in intensive nursing care. Rev Esc Enferm USP. 2018;52:e03406. DOI: http://dx.doi.org/10.1590/S1980220X2017042203406

7. Duarte, Sabrina da Costa Machado, Queiroz, Ana Beatriz Azevedo, Büscher, Andreas, \& Stipp, Marluci Andrade Conceição. (2015). Human error in daily intensive nursing care. Revista Latino-Americana de Enfermagem, 23(6), 1074 1081.https://dx.doi.org/10.1590/0104-1169.0479.2651

8. Ekram M. El sharawy, et al (2017): assessment of patient safety culture among health care workers in BeniSuef university. Vol. 35, No 3, Egyptian journal of community medicine.

9. El shafei AMH and Zayed MA (2019): Patient safety attitude in primary health care settings in Giza, Egypt: Cross-sectional study. Int J Health Plann Manage.. doi: 10.1002/hpm.2743. [Epub ahead of print]

10. Kang J, Yun S. (2016): A Grounded Theory Approach on Nurses' Experience with Workplace Bullying. J Korean Acad Nurs. ; 46(2):226-237. https://doi.org/10.4040/jkan.2016.46.2.226 
11. Lawati, M. H. A. L., Dennis, S., Short, S. D., \& Abdulhadi, N. N. (2018). Patient safety and safety culture in primary health care: a systematic review. BMC Family Practice, 19(1), 104. doi:10.1186/s12875-018-07937

12. Lee, Y., Yang, C., \& Chen, T. (2016): Barriers to incident-reporting behavior among nursing staff: A study based on the theory of planned behavior. Journal of Management \& Organization, 22(1), 1-18. doi:10.1017/jmo.2015.8

13. Magalhães FHL, Pereira ICA, Luiz RB, Barbosa MH, Ferreira MBG. (2019): Patient safety atmosphere in a teaching hospital. Rev Gaucha Enferm.; 40(spe):e20180272. doi: 10.1590/1983-1447.2019.20180272.

14. Margaret Hardt (2015): The Relationship Between Patient Safety Culture and Patient Outcomes: A Systematic Review, Journal of Patient Safety: September 2015 - Volume 11 - Issue 3 - p 135-142 . doi: 10.1097/PTS.0000000000000058

15. Patient safety standard (2016): www.healthgovernace unite.com/image/insert

16. Reis GAX, Oliveira JLC, Ferreira AMD, Vituri DW, Marcon SS, Matsuda LM.(2019) :Difficulties to implement patient safety strategies: perspectives of nurses. Rev Ga icha Enferm.;40 (esp):e20180366.doi: https://doi.org/10.1590/1983-1447.2019.20180366.

17. Wang Y, Fan Y, Wang X, Ma Y, Wu C, Shi H, Han H, Liu W, Liu C (2019): Multilevel Analysis of Individual, Organizational, and Regional Factors Associated With Patient Safety Culture: A CrossSectional Study of Maternal and Child Health Institutions in China. J Patient Saf.. doi: 10.1097/PTS.0000000000000570.

18. Zaheer S, Ginsburg LR, Wong HJ, et al (2018): Importance of safety climate, teamwork climate and demographics: understanding nurses, allied health professionals and clerical staff perceptions of patient safety. BMJ Open Quality 2018;7:e000433. doi:10.1136/ bmjoq-2018-000433 